\title{
Hypertension, obesity and STOP-Bang questionnaire in detecting obstructive sleep apnea
}

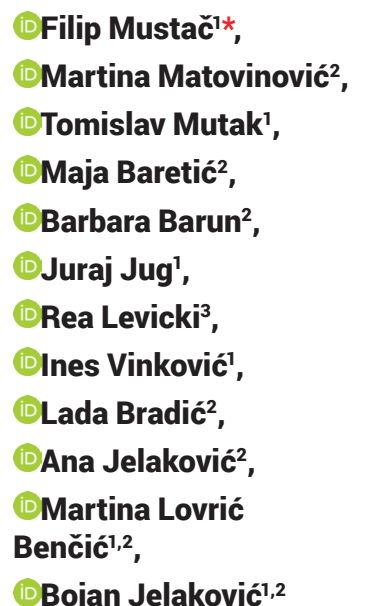

UUniversity of Zagreb School of Medicine, Zagreb, Croatia 2University of Zagreb School of Medicine, University Hospital Centre Zagreb, Zagreb, Croatia

${ }^{3}$ Požega General County Hospital, Požega, Croatia
RECEIVED:

August 5, 2019

ACCEPTED:

September 16, 2019

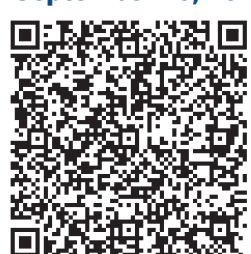

KEYWORDS: hypertension, obesity, obstructive sleep apnea, cardiovascular risk. CITATION: Cardiol Croat. 2019;14(9-10):237. | https://doi.org/10.15836/ccar2019.237

*ADDRESS FOR CORRESPONDENCE: Filip Mustač, Susedgradska 3, HR-10000 Zagreb, Croatia. / Phone: +385-919232-406 / E-mail: filip.mustac@gmail.com

ORCID: Filip Mustač, https://orcid.org/0000-0003-2851-6183 • Martina Matovinović, https://orcid.org/0000-0002-6325-7394 Tomislav Mutak, https://orcid.org/0000-0002-2791-1379 • Maja Baretić, https://orcid.org/0000-0002-7242-8407

Barbara Barun, https://orcid.org/0000-0002-1665-7491 • Juraj Jug, https://orcid.org/0000-0002-3189-1518 Rea Levicki, https://orcid.org/0000-0003-3687-1310 • Ines Vinković, https://orcid.org/0000-0003-1705-8295 Lada Bradić, https://orcid.org/0000-0001-8296-699X • Ana Jelaković, https://orcid.org/0000-0002-9262-4667 Martina Lovrić Benčić, https://orcid.org/0000-0001-8446-6120 • Bojan Jelaković, https://orcid.org/0000-0002-2546-4632

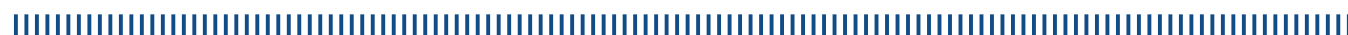

Introduction: Breathing-related sleep disorders (out of them, especially obstructive sleep apnea (OSA)) are often present in obese patients. Significant correlation between conditions such as OSA or metabolic syndrome and some anthropometric measures, most notably neck circumference (NC) has been found ${ }^{1}$. Our goal was to examine the difference in STOP-Bang questionnaire score in obese patients depending on presence of hypertension and to see whether the use of it can be useful as a screening test for OSA.

Patients and Methods: This cross-sectional study was carried out in a tertiary healthcare centre in an outpatient clinic for treatment of obesity. 49 participants (BMI $>30 \mathrm{~kg} / \mathrm{m}^{2}$ ) were included. Welch t-tests were used to compare STOP-Bang questionnaire scores to our researched subjects.

Results: Mean age was $50.29 \pm 11.91$ years. Overall mean BMI was $44.64 \pm 8.12 \mathrm{~kg} / \mathrm{m}^{2}$. There was not significant correlation between STOP-Bang questionnaire score and sex: $\mathrm{t}(9.486)=-2.17 ; \mathrm{p}=.06$, diabetes mellitus: $t(7.821)=-2.07 ; p=.07$ nor prediabetes: $t(19.696)=-0.92 ; p=.37$. However, patients with hypertension (Figure 1) had significantly higher score on STOP questionnaire than patients without hypertension: $\mathrm{t}(24)=-3.32 ; \mathrm{p}=.003$

Conclusion: Our results showed that obese patients with hypertension have higher score on the STOPBang questionnaire and consequently higher chance of OSA. Bakhai et al. have also shown that hypertension is an independent risk factor for OSA ${ }^{2}$. Thus, the STOP-Bang questionnaire could be an effective tool in obese hypertensive patients as a screening test to increase the percentage of newly diagnosed OSA and initiate timely treatment.

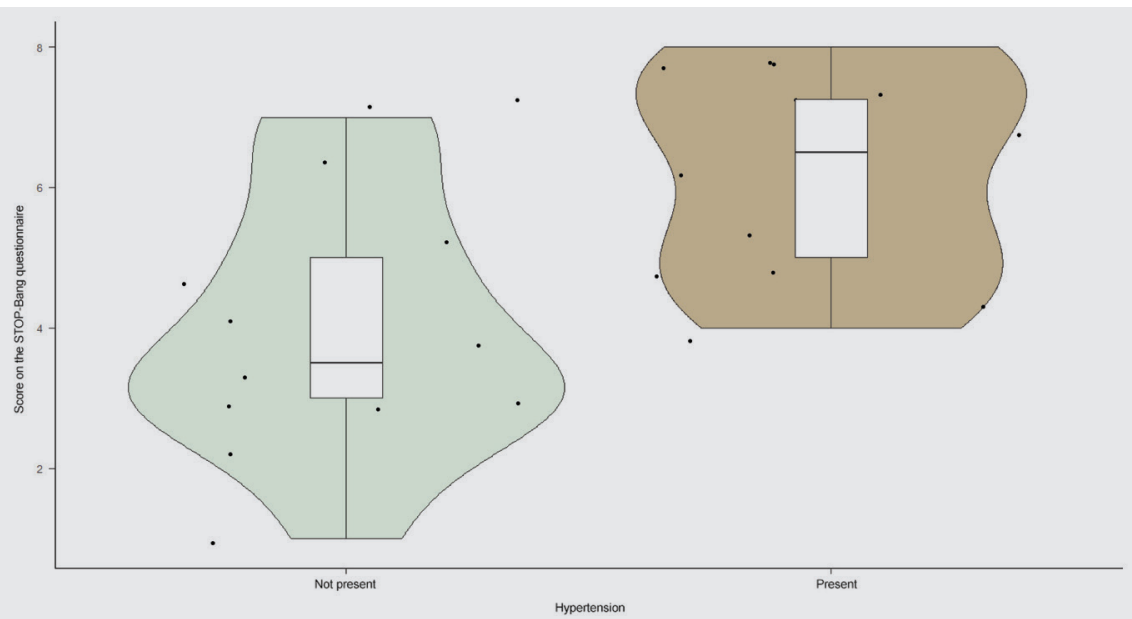

FIGURE 1. Results on the STOP-Bang questionnaire depending on the presence of hypertension.

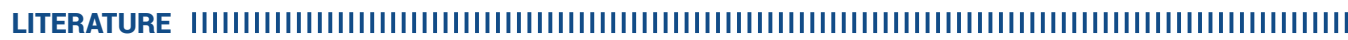

1. Cizza G, De Jonge L, Piaggi P, Mattingly M, Zhao X, Lucassen E, et al. Neck circumference is a predictor of metabolic syndrome and obstructive sleep apnea in short-sleeping obese men and women. Metab Syndr Relat Disord. 2014 May:12(4):231-41. https://doi.org/10.1089/met.2013.0093

2. Bakhai SY, Nigam M, Saeed M, Krishnan A, Reynolds JL. Improving OSA screening and diagnosis in patients with hypertension in an academic safety net primary care clinic: quality improvement project. BMJ Open Qual. 2017;6(2):e000105. https://doi.org/10.1136/bmjoq-2017-000105 